\title{
The early twentieth century warming and winter Arctic sea ice
}

\author{
V. A. Semenov ${ }^{1,2,3}$ and M. Latif ${ }^{1,4}$ \\ ${ }^{1}$ Helmholtz Centre for Ocean Research Kiel, GEOMAR, Germany \\ ${ }^{2}$ A.M. Obukhov Institute of Atmospheric Physics RAS, Moscow, Russia \\ ${ }^{3}$ Lomonosov Moscow State University, Moscow, Russia \\ ${ }^{4}$ Kiel University, Kiel, Germany \\ Correspondence to: V. A. Semenov (vsemenov@geomar.de)
}

Received: 24 April 2012 - Published in The Cryosphere Discuss.: 12 June 2012

Revised: 1 October 2012 - Accepted: 2 October 2012 - Published: 1 November 2012

\begin{abstract}
The Arctic has featured the strongest surface warming over the globe during the recent decades, and the temperature increase has been accompanied by a rapid decline in sea ice extent. However, little is known about Arctic sea ice change during the early twentieth century warming (ETCW) during 1920-1940, also a period of a strong surface warming, both globally and in the Arctic. Here, we investigate the sensitivity of Arctic winter surface air temperature (SAT) to sea ice during $1875-2008$ by means of simulations with an atmospheric general circulation model (AGCM) forced by estimates of the observed sea surface temperature (SST) and sea ice concentration. The Arctic warming trend since the 1960s is very well reproduced by the model. In contrast, ETCW in the Arctic is hardly captured. This is consistent with the fact that the sea ice extent in the forcing data does not strongly vary during ETCW. AGCM simulations with observed SST but fixed sea ice reveal a strong dependence of winter SAT on sea ice extent. In particular, the warming during the recent decades is strongly underestimated by the model, if the sea ice extent does not decline and varies only seasonally. This suggests that a significant reduction of winter Arctic sea ice extent may have also accompanied the early twentieth century warming, pointing toward an important link between anomalous sea ice extent and Arctic surface temperature variability.
\end{abstract}

\section{Introduction}

The anomalously warm temperatures in the Arctic during the early twentieth century warming (ETCW) (Bengtsson et al., 2004; Wood and Overland, 2010) have been exceeded only during the most recent years (Fig. 1). The recent sea ice loss and Arctic warming is Arctic-wide and consistent with increasing atmospheric greenhouse gas concentrations. For the ETCW, the temperature anomalies were more regional being concentrated in the Atlantic portion of the Arctic, suggesting a stronger contribution from natural variability (Wood and Overland, 2010). The origin of the ETCW is still under discussion and could be a key for understanding past and predicting future Arctic climate change. Whereas the recent Arctic warming since the 1970s has been accompanied by a strong reduction in sea ice extent, only little is known about sea ice during ETCW, particularly during the cold half of the year, when surface air temperature (SAT) changes exceeded those in summer by a factor of two (Overland et al., 2004; Semenov, 2007) thereby providing the major contribution to the annual mean. Both the cold season (November through April) SAT and sea ice extent have exhibited strong sustained trends since the 1970s with some higher-frequency variability superimposed (Fig. 1). The datasets used here are CRUTEM3 (Brohan et al., 2006) and HadISST1.1 (Rayner et al., 2003). The picture drastically changes, however, during ETCW. In particular, no decadal-scale decline in sea ice extent is seen during ETCW that would be comparable to that observed during the recent decades. The possible reason for this apparent inconsistency between the warming and sea ice behaviour during the recent decades and that during ETCW is the topic of the present study.

The Hadley Centre sea surface temperature (SST) and sea ice gridded dataset (HadISST1.1) comprises different observational data (Rayner et al., 2003). The winter Arctic sea ice area anomalies from HadISST1.1 (Fig. 1) do not depict any strong changes before 1960. The sources for the Arctic sea 


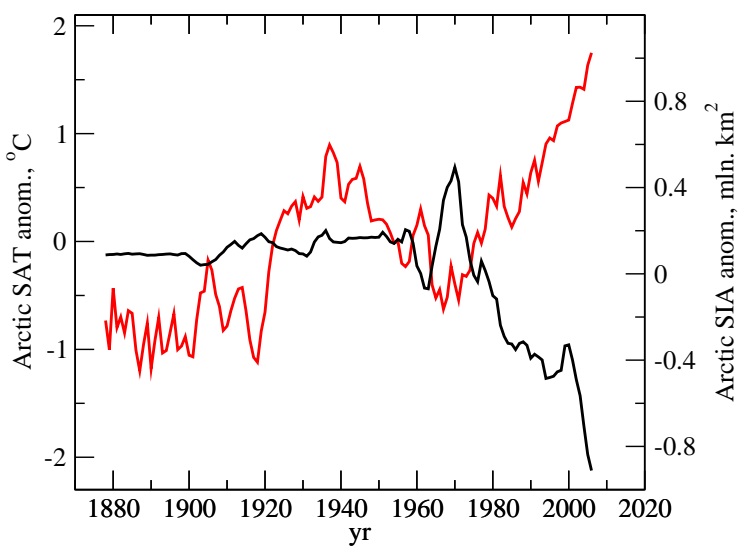

Fig. 1. Arctic $\left(60^{\circ} \mathrm{N}-90^{\circ} \mathrm{N}\right)$ cold season (November-April) land SAT anomalies $\left({ }^{\circ} \mathrm{C}\right)$ from CRUTEM3, and $\mathrm{NH}$ sea ice area anomalies $\left(10^{6} \mathrm{~km}^{2}\right)$ from HadISST1.1. A 5-yr running mean filter was applied to both datasets.

ice data are highly inhomogeneous, and data reliability and spatial coverage drop sharply before the satellite era, which started in 1978 (Walsh and Chapman, 2001). The data for 1953-1977 are compiled from several national sources based on different observational methods (without any data from the former Soviet Union) (Walsh and Johnson, 1979). The data prior to 1953 are very sparse and based on records from Danish Meteorological Institute and Norwegian Polar Institute. Data quality is particularly bad for winter when no data were available during 1901-1965 and temporal interpolation was applied using summer data (Rayner et al., 2003). Thus the sea extent during ETCW and before cannot be considered reliable, as also somewhat suggested by the almost constant values during this time period (Fig. 1). This also applies to summer (not shown).

The Arctic surface climate during the last century is characterized by strong multi-decadal variability with ETCW being a part of it. Some first indications of a transition to a warmer climate state have been presented already in the 1920s (Ifft, 1922). Concurrent multi-decadal variations have been revealed in the Arctic surface air temperature, the Arctic sea level pressure, and the temperature of Atlantic water layer and freshwater content of the Arctic Ocean (Bengtsson et al., 2004; Overland et al., 2004; Polyakov et al., 2003a, b, 2004, 2008). Regional data from the eastern Arctic and the Nordic Seas depict a considerable reduction in sea ice extent or a retreat of the ice edge during ETCW (Alekseev et al., 2007, 2009; Polyakov et al., 2003a; Divine and Dick, 2006; Alekseev et al., 2007). An Arctic sea ice decline is also suggested by some whole-Arctic reconstructions (Zakharov, 1997; Johannessen et al., 2004). Further evidence for shrinking sea ice extent during ETCW has been presented by Zakharov (2003). Most of the available sea ice data for the early 20 th century period cover the warm half of a year, leaving a much higher uncertainty for estimating sea ice variations during the winter half.

Winter Arctic SAT and sea ice extent are closely linked as shown by observational analysis and climate model simulations (Bengtsson et al., 2004; Goosse and Holland, 2005; Semenov, 2008; Johannessen et al., 2004; Mysak et al., 1990). The multi-decadal SAT variability in the Arctic (Semenov and Bengtsson, 2003) including the ETCW SAT anomaly (Bengtsson et al., 2004) is strongest near the sea ice edge in the Atlantic sector, and pan-Arctic station data show positive temperature anomalies during ETCW practically at all longitudes except for the Pacific sector (Overland et al., 2004; Wood and Overland, 2010; Wood et al., 2010). All the above and the apparent mismatch between the SAT and the sea ice evolution during the first half of the 20th century (Fig. 1) suggest a possibility of a strongly reduced Arctic sea ice extent during ETCW.

Here, we indirectly address the question as to whether ETCW could have been accompanied by a strong reduction in winter Arctic sea ice extent by comparing 20th century Arctic land SAT obtained from meteorological stations to those from an atmosphere model forced by observational estimates of SST and sea ice extent. Such an approach was used in many previous studies which showed that, on continental scales, oceanic boundary forcing explains a major part of the observed multi-decadal SAT variability during the last century (e.g. Dommenget, 2009; Hoerling et al., 2008). We performed two ensemble integrations with an atmospheric general circulation model (AGCM) driven with observed SST. Sea ice concentration (SIC) varies inter-annually only in one ensemble, while it is prescribed from climatology in the other. This approach, although not accounting for full oceanatmosphere-sea ice coupling, provides an estimate of the sea ice feedback to Arctic SAT.

\section{Model simulations and data}

The simulations were performed with the ECHAM5 AGCM (Roeckner et al., 2003). The model version used here has a horizontal resolution of $\mathrm{T} 31\left(3.75^{\circ} \times 3.75^{\circ}\right)$ and 19 vertical levels. Two ensemble simulations were conducted for the period 1875-2008. Each ensemble consists of 7 realizations with identical boundary forcing but different atmospheric initial conditions. In both ensembles, estimates of observed radiative forcing were prescribed including greenhouse gases, sulphate aerosols, and ozone. Other external forcings such as solar forcing were not considered. One ensemble (HadISST) used the full time-varying SST and SIC from HadISST1.1. The other (HadISST-fixed ice) used the same SST forcing but fixed monthly mean sea ice climatology calculated from the period 1941-1950.

The simulated land SAT averaged over the sub-Arctic and Arctic latitudes (north of $60^{\circ} \mathrm{N}$ ) was compared to the observations from the Climatic Research Unit Temperature dataset 


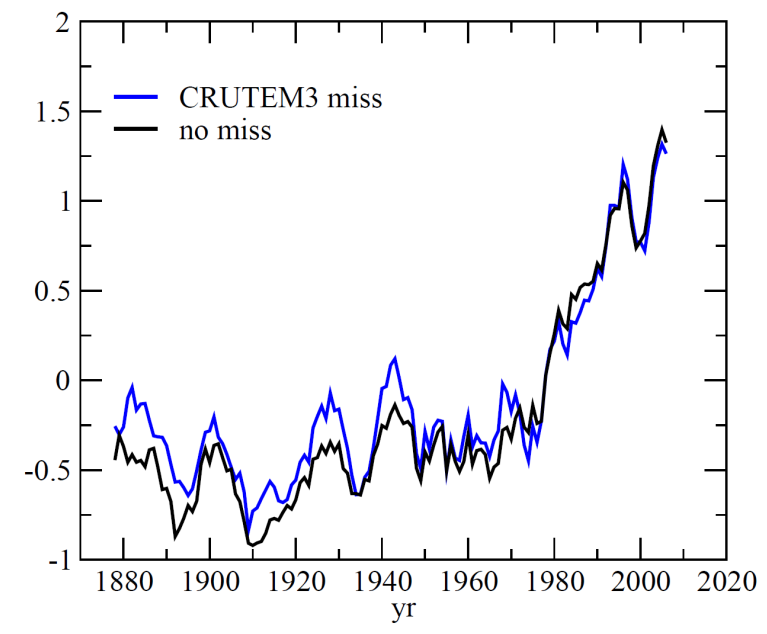

Fig. 2. Arctic cold season (November-April) SAT anomalies $\left({ }^{\circ} \mathrm{C}\right)$ simulated in the HadISST ensemble mean with (blue) and without (black) data sampling according to CRUTEM3 data.

CRUTEM3 (Brohan et al., 2006). The gridded data contain many gaps or missing values particularly during the first half of the 20th century. For consistency, the monthly model SATs have been interpolated on the CRUTEM3 grid and sampled exactly in the same way as in CRUTEM3. It is important to note that, despite the scarce data, especially during the earlier periods, the CRUTEM3 sampling is sufficient to represent the whole-Arctic SAT (land and ocean north of $60^{\circ} \mathrm{N}$ ) simulated by the model. This is illustrated by Fig. 2 which shows the winter (November-April) Arctic SAT anomalies from the HadISST experiment computed as the ensemble mean of the model data with full and with CRUTEM3 sampling. There is virtually no difference between the two time series after 1950. There are, however, some noticeable discrepancies during the earlier period, but these do not exceed $0.3^{\circ} \mathrm{C}$.

The following analysis is restricted to the cold half of the year (November-April) which exhibited the strongest SAT trend during the recent decades and also during ETCW. A 5 -yr running mean filter was applied to present the results, as the focus of this study is on multi-decadal Arctic SAT changes.

\section{Results}

The Arctic cold season land SAT anomalies simulated by ECHAM5 in the HadISST ensemble (Fig. 3) are shown together with the observations from CRUTEM3, and those from NCEP/NCAR reanalysis (Kalnay et al., 1996). All data are sampled in the same way as CRUTEM3 with the anomalies computed relative to 1961-1990. The NCEP/NCAR SAT follows very closely the observed anomalies during the overlapping period. The ECHAM5 ensemble mean is an estimate of the changes caused by external and surface forcing. The ensemble spread reflecting internal atmospheric variability is

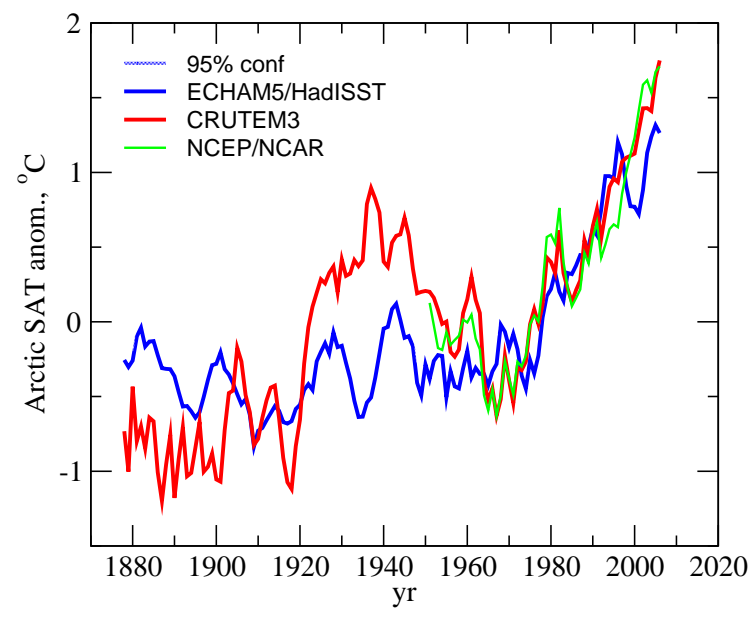

Fig. 3. Arctic $\left(60^{\circ} \mathrm{N}-90^{\circ} \mathrm{N}\right)$ cold season (November-April) land SAT anomalies $\left({ }^{\circ} \mathrm{C}\right)$ as observed (CRUTEM3, red) and computed in the ECHAM5 (HadISST) ensemble integrations. The thick blue line represents the ensemble mean; the dashed blue lines show the $95 \%$ confidence interval (according to Student's $t$-test) estimated from the ensemble spread. The green line depicts the NCEP/NCAR reanalysis SAT. A 5-yr running mean filter was applied to all data.

indicated by the dashed blue lines $(95 \%$ confidence interval). The model reproduces well the observed Arctic warming trend of about $2^{\circ} \mathrm{C}$ since the last major SAT minimum in the 1960s. There are, however, some differences. A cooling is simulated around 2000 which is not present in CRUTEM3. Furthermore, the model slightly underestimates the very recent warming by some $0.5^{\circ} \mathrm{C}$, although at least half of this mismatch could be explained by internal atmospheric variability. In contrast to the most recent warming, the ETCW is not reproduced by ECHAM5 and clearly outside the internal variability range of the model for more than two decades.

The role of sea ice in long-term Arctic SAT variability can be evaluated by comparing the HadISST ensemble to the HadISST-fixed ice ensemble without inter-annually varying sea ice (Fig. 4a). The ensemble mean SATs simulated in the two experiments follow each other closely up to about 1970 . Thereafter they start to diverge, with significantly lower SAT simulated in HadISST-fixed ice: the warming in the fixed sea ice case is about $0.7^{\circ} \mathrm{C}(40 \%)$ less than that in HadISST with varying sea ice. The SAT differences during the late 19th and early 20th century are statistically insignificant and within the ensemble spread. The differences between the two ensemble mean SATs are shown for the two samplings (one as in CRUTEM3, the other with whole-Arctic coverage) together with the corresponding differences in sea ice extent (Fig. 4b). Clearly, there is a close inverse relationship between temperature and sea ice during the last four decades. This highlights the important link between sea ice extent and SAT changes during the recent decades. During ETCW, the SAT differences between the two ensembles are generally small for both samplings. Furthermore, the difference 

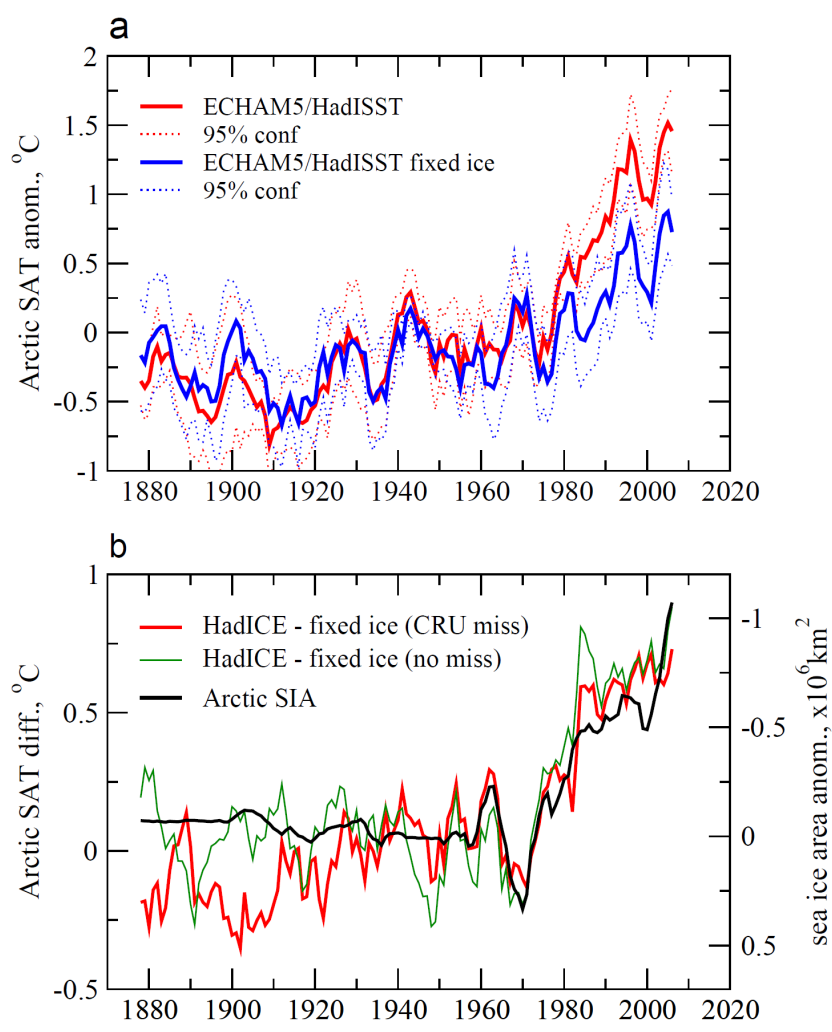

Fig. 4. (a) Arctic land SAT cold season anomalies $\left({ }^{\circ} \mathrm{C}\right)$ as simulated in the HadISST (red) and HadISST-fixed ice ensemble (blue). The ensemble means are given as solid bold lines, the confidence intervals as thin dashed lines; (b) difference between the ensemble mean SATs shown in (a) with (red) and without (green) data sampling according to CRUTEM3 data. The black line depicts the inverted (see right y-axis) sea ice area differences $\left(10^{6} \mathrm{~km}^{2}\right)$ (HadISST1.1 - climatology of the period 1941-1950). All time series are smoothed with a 5-yr running mean filter.

in sea ice extent during ETCW is also modest, as expected from Fig. 1 depicting the absence of large SIC changes in HadISST1.1. This indicates the importance of sea ice for reproducing SAT in our model and suggests that sea ice may have played a strong role not only during the recent decades but also during ETCW.

The cold season SAT difference between the two ensemble means (HadISST minus HadISST-fixed ice) during 19892008 is strongest in the Barents and Kara Sea regions and over the northern part of the Greenland Sea with values reaching more than $2^{\circ} \mathrm{C}$ (Fig. 5). Secondary, smaller, maxima are located in the northern Labrador Sea, Bering and Okhotsk Seas. Overall, the pattern looks very similar to that of ETCW identified by Bengtsson et al. (2004) based on another SAT analysis (Kuzmina et al., 2008). The pattern is also reminiscent of the multi-decadal SAT variability pattern during the 20th century (Semenov, 2007; Semenov and Bengtsson, 2003). The similarity of the patterns also supports the

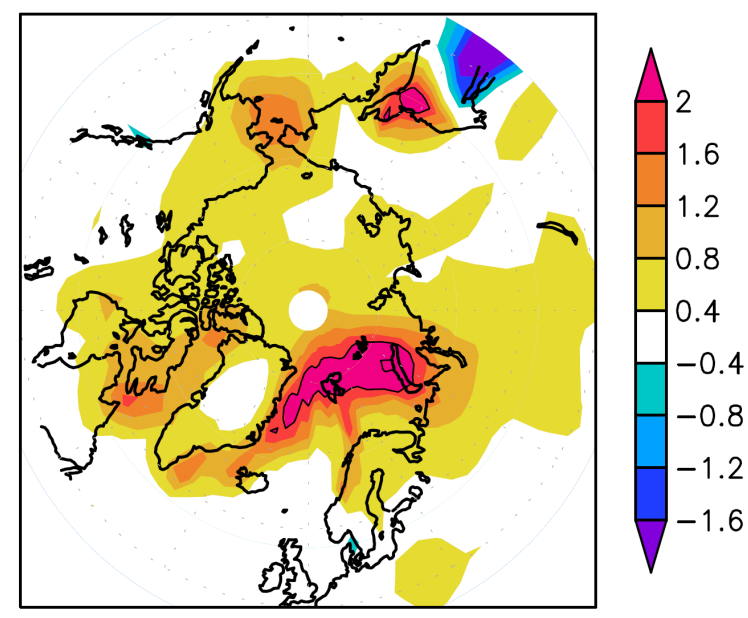

Fig. 5. Cold season (November-April) ensemble mean SAT differences $\left({ }^{\circ} \mathrm{C}\right)$ averaged over the period 1989-2008 between the HadISST and HadISST-fixed sea ice ensembles.

notion that the ETCW was accompanied by a strongly reduced winter sea ice extent.

\section{Discussion}

We suggest that the early twentieth century warming (ETCW) in winter was accompanied by a strongly reduced Arctic sea ice extent, which in turn considerably contributed to Arctic surface warming during that time. However, this could be shown only indirectly by means of an AGCM. The latter cannot reproduce the strong positive winter Arctic SAT anomaly during ETCW when forced by SST and SIC from observational data (HadISST). In contrast, the most recent warming phase starting in the mid-1960s is well simulated by the model. We hypothesize that the surface forcing data used to drive the model are not reliable, as they do not depict any strong sea ice extent changes prior to 1960, especially not during ETCW.

We cannot directly infer from our forced AGCM simulations the ETCW mechanism, which may essentially involve coupled ocean-sea ice-atmosphere dynamics. However, the uncoupled approach helps to evaluate the feedback of sea ice extent on the surface temperature. The comparison of the numerical experiments with and without inter-annually varying sea ice extent reveals a strong dependence of the simulated Arctic SAT on sea ice changes on the order of $0.6^{\circ} \mathrm{C}$ warming per $10^{6} \mathrm{~km}^{2}$ of sea ice area reduction.

There can be proposed other explanations than sea ice for the mismatch between the simulated and observed Arctic surface air temperatures during ETCW. First, a sampling effect due to the lack of surface temperature observations may be responsible. This can be basically ruled out, as the way of sampling imposes only minor changes in the model (Fig. 2). Second, the experiments do not consider solar forcing and 


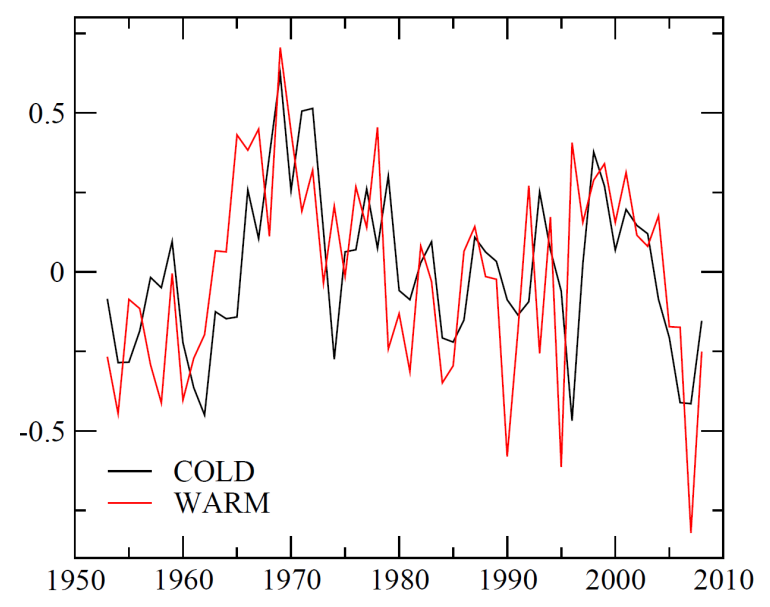

Fig. 6. Detrended Northern Hemisphere sea ice area anomalies during 1953-2008, in $10^{6} \mathrm{~km}^{2}$ (HadISST1.1 data) for the cold (November-April) and warm (May-October) half of the year.

may not correctly represent stratospheric ozone and aerosol forcing, all of which could have contributed to ETCW. It should be noted, however, that the CMIP3 models (Meehl et al., 2007) in the ensemble mean considerably underestimate ETCW when forced by all known forcing agents (20C3M simulations) (Wang et al., 2007). Further, a major part of the large-scale radiative forcing is already reflected in the prescribed historical boundary forcing. Finally, we cannot exclude beforehand the possibility that ETCW constitutes a strong realization of internal multi-decadal atmospheric variability. However, the latter is not supported by our model ensembles each consisting of 7 members, as not a single realization featured an anomaly comparable to ETCW by its amplitude and duration. Model bias needs to be considered in this context. Semenov et al. (2008) show, however, that the AGCM, when coupled to an ocean GCM, simulates internal atmospheric variability in the Arctic/North Atlantic sector that is consistent with observations.

A more plausible hypothesis that would readily explain the absence of the ETCW in the AGCM simulations is a concurrent reduced Arctic sea ice cover that is not present in the surface forcing dataset. Particularly important are the sea ice anomalies in the Barents and Kara Seas where observations indeed indicate a considerable retreat of summer sea ice extent during the 1930s and 1940s (Alekseev et al., 2007, 2009; Johannessen et al., 2004; Polyakov et al., 2003a; Divine and Dick, 2006; Zakharov, 2003). It is important to note in this context that on decadal and longer timescales observed summer and winter sea ice extent variations exhibit a high coherence during 1953-2008 (Fig. 6), after removing the linear trend. However, the linear trend is more than two times steeper in the summer half of the year, while inter-decadal variations are practically of the same amplitude.

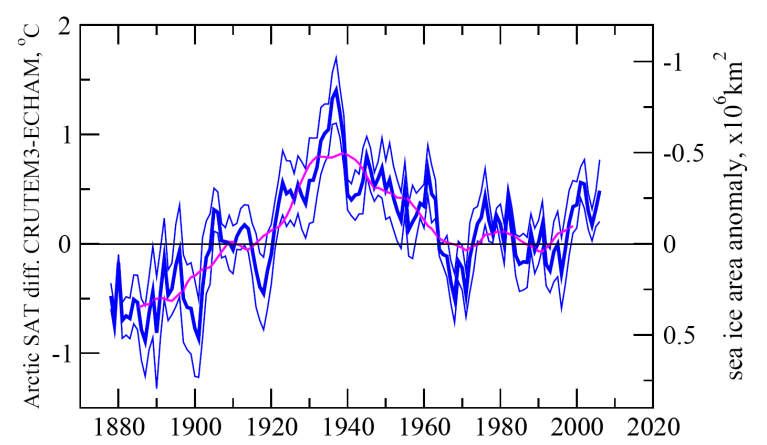

Fig. 7. Ensemble mean difference $\left({ }^{\circ} \mathrm{C}\right)$ between Arctic cold season land SAT from the ECHAM5 (HadISST) ensemble (thick blue line) and the observations (CRUTEM3). The thin blue lines show the $95 \%$ confidence interval. A 5-yr running mean was applied. The magenta line is ensemble mean difference smoothed with a $15-\mathrm{yr}$ running mean. Left axis is for SAT anomalies; right axis represents sea ice area anomalies $\left(10^{6} \mathrm{~km}^{2}\right)$ associated with temperature difference as estimated from model sensitivity experiments.

Recent studies suggested a major contribution of sea ice loss to the accelerated Arctic SAT increase during the recent decades (Screen and Simmonds, 2010; Semenov et al., 2010; Serreze et al., 2009). Furthermore, the observed warming pattern during the late 20th and early 21 st century is similar to that during ETCW. This motivated us to estimate the magnitude of the possible reduction in winter sea ice extent during ETCW (Fig. 7) by computing an SAT difference-sea ice extent regression using the two model ensembles with and without varying sea ice (Fig. 3). The analysis yields a winter sea ice extent change during ETCW on the order of $0.8 \times 10^{6} \mathrm{~km}^{2}$, which is comparable to the decrease during the recent decades (see Fig. 1).

Our model results imply that a relatively strong sea ice retreat may have played a prominent role in driving ETCW in the Arctic, also suggesting a possible contribution from internal multi-decadal Atlantic Ocean variability, as previously hypothesized in several studies (Goosse and Holland, 2005; Jungclaus et al., 2005; Levitus et al., 2009; Semenov, 2008; Semenov et al., 2010; Mahajan et al., 2012). Analysis of extended Arctic temperature records since the 19th century suggests, however, that ETCW in the Arctic was an irregular fluctuation rather than a part of a quasi-periodic process (Wood et al., 2010). Changes in ocean heat transport or atmospheric circulation anomalies could trigger a prolonged natural fluctuation such as ETCW, as they can be amplified through local positive feedbacks between the sea ice, the ocean and the atmosphere (Bengtsson et al., 2004; Wood and Overland, 2010).

Control integrations from the CMIP3 ensemble demonstrate that internal variability is capable to produce strong fluctuations of the wintertime Arctic sea cover that are comparable or even surpass our indirect ETCW AGCM-based estimate. Seven models out of twenty showed multi-decadal 


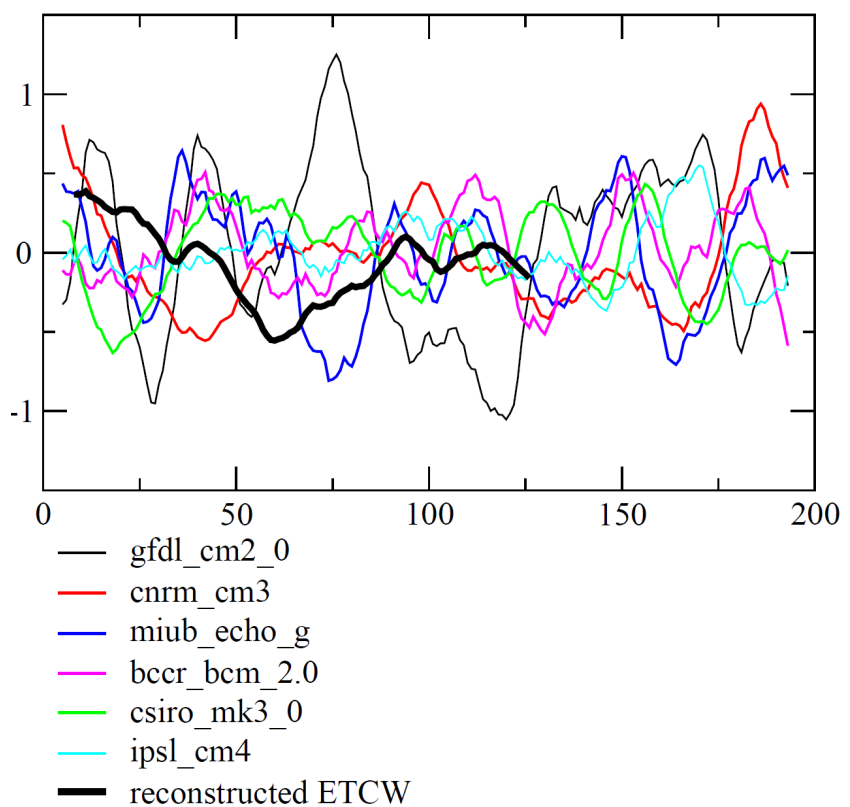

Fig. 8. Inter-decadal variations of the winter (November-April) Arctic sea ice area anomalies $\left(10^{6} \mathrm{~km}^{2}\right)$ as simulated in selected CMIP3 control experiments and the ETCW sea anomaly as estimated from model sensitivity experiments (Fig. 7). All time series are smoothed with 11-yr running mean filter.

sea ice area fluctuations with a magnitude exceeding $0.8 \times$ $10^{6} \mathrm{~km}^{2}$, and another five sea ice area changes of at least $0.5 \times 10^{6} \mathrm{~km}^{2}$. Six of the former, excluding the one with unrealistically large (about $2.5 \times 10^{6} \mathrm{~km}^{2}$ ) sea ice changes, are shown in Fig. 8 together with the estimated sea ice anomalies during ETCW from Fig. 7. Furthermore, the coupled models, consistent with the inferences drawn here, reveal a high anticorrelation between Arctic sea ice extent and Arctic surface temperature changes. For the majority of the CMIP3 models, the anti-correlation is stronger than -0.6 (and even -0.7 for 9 models). Thus internal multi-decadal climate fluctuation is a potential candidate to explain the early twentieth century warming in the Arctic.

Acknowledgements. The authors would like to thank James Overland and John Walsh for constructive reviews, and Genrikh Alekseev for very helpful comments. We are thankful to Noel Keenlyside for his help with the setup of the model. This work was supported by the European Union's THOR project, NATO Collaborative Linkage Grant 983725, Russian Foundation for Basic Research (11-05-00579, 12-05-00617), Programs of Russian Academy of Sciences $(4,31)$ and the Nordatlantik project of the German Ministry of Research (BMBF). The model runs were performed at the Northern Germany High Performance Computing Center (HLRN).

Edited by: E. Hanna

\section{References}

Alekseev, G. V., Kuzmina, S. I., Nagurny, A. P., and Ivanov, N. E.: Arctic sea ice data sets in the context of the climate change during the 20th century, in: Climate variability and extremes during the past 100 years, Adv. Global Change Res., Springer, 47-63, 2007.

Alekseev, G. V., Danilov, A. I., Kattsov, V. M., Kuz'mina, S. I., and Ivanov, N. E.: Changes in the climate and sea ice of the Northern Hemisphere in the 20th and 21st centuries from data of observations and modeling, Izvestiya Atmos. Ocean. Phys., 45, 675-686, doi:10.1134/s0001433809060012, 2009.

Bengtsson, L., Semenov, V. A., and Johannessen, O. M.: The early twentieth-century warming in the Arctic - A possible mechanism, J. Climate, 17, 4045-4057, 2004.

Brohan, P., Kennedy, J. J., Harris, I., Tett, S. F. B., and Jones, P. D.: Uncertainty estimates in regional and global observed temperature changes: A new data set from 1850, J. Geophys. Res.Atmos., 111, D12106, doi:10.1029/2005jd006548, 2006.

Divine, D. V. and Dick, C.: Historical variability of sea ice edge position in the Nordic Seas, J. Geophys. Res.-Ocean., 111, C01001, doi:10.1029/2004jc002851, 2006.

Dommenget, D.: The Ocean's Role in Continental Climate Variability and Change, J. Climate, 22, 4939-4952, doi:10.1175/2009jcli2778.1, 2009.

Goosse, H. and Holland, M. M.: Mechanisms of decadal arctic climate variability in the community climate system model, version 2 (CCSM2), J. Climate, 18, 3552-3570, 2005.

Hoerling, M., Kumar, A., Eischeid, J., and Jha, B.: What is causing the variability in global mean land temperature?, Geophys. Res. Lett., 35, L23712, doi:10.1029/2008g1035984, 2008.

Ifft, G. N.: The Changing Arctic, Mon. Weather Rev., 50, p. 589, 1922.

Johannessen, O. M., Bengtsson, L., Miles, M. W., Kuzmina, S. I., Semenov, V. A., Alekseev, G. V., Nagurnyi, A. P., Zakharov, V. F., Bobylev, L. P., Pettersson, L. H., Hasselmann, K., and Cattle, A. P.: Arctic climate change: observed and modelled temperature and sea-ice variability, Tellus Ser. a-Dynamic Meteorology and Oceanography, 56, 328-341, 2004.

Jungclaus, J. H., Haak, H., Latif, M., and Mikolajewicz, U.: ArcticNorth Atlantic interactions and multidecadal variability of the meridional overturning circulation, J. Climate, 18, 4013-4031, 2005.

Kalnay, E., Kanamitsu, M., Kistler, R., Collins, W., Deaven, D., Gandin, L., Iredell, M., Saha, S., White, G., Woollen, J., Zhu, Y., Chelliah, M., Ebisuzaki, W., Higgins, W., Janowiak, J., Mo, K. C., Ropelewski, C., Wang, J., Leetmaa, A., Reynolds, R., Jenne, R., and Joseph, D.: The NCEP/NCAR 40-year reanalysis project, B. Am. Meteorol. Soc., 77, 437-471, 1996.

Kuzmina, S. I., Johannessen, O. M., Bengtsson, L., Aniskina, O. G., and Bobylev, L. P.: High northern latitude surface air temperature: comparison of existing data and creation of a new gridded data set 1900-2000, ISI:000252931500009, 289-304, 2008.

Levitus, S., Matishov, G., Seidov, D., and Smolyar, I.: Barents Sea multidecadal variability, Geophys. Res. Lett., 36, L19604, doi:10.1029/2009g1039847, 2009.

Mahajan, S., Zhang, R., and Delworth, T. L.: Impact of the Atlantic Meridional Overturning Circulation (AMOC) on Arctic Surface Air Temperature and Sea Ice Variability, J. Climate, 24, 65736581, doi:10.1175/2011jcli4002.1, 2012. 
Meehl, G. A., Covey, C., Delworth, T., Latif, M., McAvaney, B., Mitchell, J. F. B., Stouffer, R. J., and Taylor, K. E.: The WCRP CMIP3 multimodel dataset - A new era in climate change research, B. Am. Meteorol. Soc., 88, 1383-1394, doi:10.1175/bams-88-9-1383, 2007.

Mysak, L. A., Manak, D. K., and Marsden, R. F.: Sea-ice anomalies observed in the Greenland and Labrador Seas during 1901-1984 and their relation to an interdecadal Arctic climate cycle, Clim. Dynam., 5, 111-133, 1990.

Overland, J. E., Spillane, M. C., Percival, D. B., Wang, M. Y., and Mofjeld, H. O.: Seasonal and regional variation of pan-Arctic surface air temperature over the instrumental record, J. Climate, 17, 3263-3282, 2004.

Polyakov, I. V., Alekseev, G. V., Bekryaev, R. V., Bhatt, U. S., Colony, R., Johnson, M. A., Karklin, V. P., Walsh, D., and Yulin, A. V.: Long-term ice variability in Arctic marginal seas, J. Climate, 16, 2078-2085, 2003a.

Polyakov, I. V., Bekryaev, R. V., Alekseev, G. V., Bhatt, U. S., Colony, R. L., Johnson, M. A., Maskshtas, A. P., and Walsh, D.: Variability and trends of air temperature and pressure in the maritime Arctic, 1875-2000, J. Climate, 16, 20672077, doi:10.1175/1520-0442(2003)016<2067:vatoat>2.0.co;2, 2003 b.

Polyakov, I. V., Alekseev, G. V., Timokhov, L. A., Bhatt, U. S., Colony, R. L., Simmons, H. L., Walsh, D., Walsh, J. E., and Zakharov, V. F.: Variability of the intermediate Atlantic water of the Arctic Ocean over the last 100 years, J. Climate, 17, 4485-4497, doi:10.1175/jcli-3224.1, 2004.

Polyakov, I. V., Alexeev, V. A., Belchansky, G. I., Dmitrenko, I. A., Ivanov, V. V., Kirillov, S. A., Korablev, A. A., Steele, M., Timokhov, L. A., and Yashayaev, I.: Arctic ocean freshwater changes over the past 100 years and their causes, J. Climate, 21, 364-384, doi:10.1175/2007jcli1748.1, 2008.

Rayner, N. A., Parker, D. E., Horton, E. B., Folland, C. K., Alexander, L. V., Rowell, D. P., Kent, E. C., and Kaplan, A.: Global analyses of sea surface temperature, sea ice, and night marine air temperature since the late nineteenth century, J. Geophys. Res.Atmos., 108, 4407, doi:10.1029/2002jd002670, 2003.

Roeckner, E., Bäuml, G., Bonaventura, L., Brokopf, R., Esch, M., Giorgetta, M., Hagemann, S., Kirchner, I., Kornblueh, L., Manzini, E., Rhodin, A., Schlese, U., Schulzweida, U., and Tompkins, A.: The atmospheric general circulation model ECHAM 5, Part I: Model description, Max Planck Inst. Meteorol., Hamburg, 2003.

Screen, J. A. and Simmonds, I.: The central role of diminishing sea ice in recent Arctic temperature amplification, Nature, 464, 1334-1337, doi:10.1038/nature09051, 2010.
Semenov, V. A.: Structure of temperature variability in the high latitudes of the Northern Hemisphere, Izvestiya Atmos. Ocean. Phys., 43, 687-695, doi:10.1134/s0001433807060023, 2007.

Semenov, V. A.: Influence of oceanic inflow to the Barents Sea on climate variability in the Arctic region, Dokl. Earth Sci., 418, 91-94, doi:10.1134/s1028334x08010200, 2008.

Semenov, V. A. and Bengtsson, L.: Modes of the wintertime Arctic temperature variability, Geophys. Res. Lett., 30, 1781, doi:10.1029/2003g1017112, 2003.

Semenov, V. A., Latif, M., Jungclaus, J. H., and Park, W.: Is the observed NAO variability during the instrumental record unusual?, Geophys. Res. Lett., 35, L11701, doi:10.1029/2008g1033273, 2008.

Semenov, V. A., Latif, M., Dommenget, D., Keenlyside, N. S., Strehz, A., Martin, T., and Park, W.: The Impact of North Atlantic-Arctic Multidecadal Variability on Northern Hemisphere Surface Air Temperature, J. Climate, 23, 5668-5677, doi:10.1175/2010jcli3347.1, 2010.

Serreze, M. C., Barrett, A. P., Stroeve, J. C., Kindig, D. N., and Holland, M. M.: The emergence of surface-based Arctic amplification, The Cryosphere, 3, 11-19, doi:10.5194/tc-3-11-2009, 2009.

Walsh, J. E. and Chapman, W. L.: 20th-century sea-ice variations from observational data, in: Annals of Glaciology, edited by: Jeffries, M. O. and Eicken, H., Ann. Glaciol., 33, 444-448, 2001.

Walsh, J. E. and Johnson, C. M.: Analysis of Arctic sea ice fluctuations, 1953-77, J. Phys. Oceanogr., 9, 580-591, 1979.

Wang, M. Y., Overland, J. E., Kattsov, V., Walsh, J. E., Zhang, X. D., and Pavlova, T.: Intrinsic versus forced variation in coupled climate model simulations over the Arctic during the twentieth century, J. Climate, 20, 1093-1107, doi:10.1175/jcli4043.1, 2007.

Wood, K. R. and Overland, J. E.: Early 20th century Arctic warming in retrospect, Int. J. Climatol., 30, 1269-1279, doi:10.1002/joc.1973, 2010.

Wood, K. R., Overland, J. E., Jonsson, T., and Smoliak, B. V.: Air temperature variations on the Atlantic-Arctic boundary since 1802, Geophys. Res. Lett., 37, L17708, doi:10.1029/2010g1044176, 2010.

Zakharov, V. F.: Sea ice in the climate system, World Meteorological Organization, 1997.

Zakharov, V. F.: Variations of sea ice area during XX century from historical data, in: Arctic Environment Variability in the Context of the Global Change, edited by: Bobylev, L. P., Kondratyev, K. A., and Johannessen, O. M., Springer-Praxis, 107-236, 2003. 